\title{
La efectiva protección de los consumidores. Un nuevo aporte del Tribunal de Justicia de la Unión Europea a la integración europea
}

\author{
The effective protection of the consumers. \\ A new contribution of The Court of \\ Justice of the European Union to the \\ european integration
}

Gabriela Prado Prado*

\begin{abstract}
RESUMEN
En el marco de la protección de los derechos de los consumidores, este trabajo aborda los principales efectos que la jurisprudencia del Tribunal de Justicia de la Unión Europea ha provocado respecto de aquellos afectados por cláusulas abusivas en sus contratos hipotecarios. Para ello, se plantea la existencia de dos efectos jurídicos relevantes en dicha jurisprudencia: por una parte, el reforzamiento del principio de efectividad procesal en la declaración de nulidad de dichas cláusulas y, por otra, el fin de la incertidumbre sobre los efectos restitutorios que origina dicha declaración. Así, luego del análisis de estos efectos, el trabajo concluye que dicha jurisprudencia ha reforzado progresivamente la protección de los consumidores, aportando al proceso de integración europea.
\end{abstract}

Profesora asociada, Departamento de Ciencias Jurídicas de la Universidad de Atacama. Doctora en Derecho y Diplomada en Derecho Comunitario y Derecho Económico Europeo, Universidad de Salamanca. Pertenece a ECSA-Chile y a la Red Nacional de Aprendizaje y Servicio. Es miembro Capitular de la Academia Chilena de Ciencias Sociales, Políticas y Morales del Instituto de Chile. Correo electrónico: gabriela.prado@uda.cl. ORCID: 0000-0003-0573-3222. Recibido: 12 de julio de 2019. Modificado: 24 de junio de 2020. Aceptado: 25 de junio de 2020. 
Palabras clave: Unión Europea - Tribunal de Justicia de la Unión Europea - Derechos de los Consumidores - cláusulas abusivas - contratos hipotecarios.

\begin{abstract}
In the framework of the protection of consumer rights, this work addresses the main effects that the jurisprudence of the Court of Justice of the European Union has had on those affected by unfair terms in their mortgage contracts. For this, the existence of two relevant legal effects in said jurisprudence is raised; on the one hand, the reinforcement of the principle of procedural effectiveness in the declaration of nullity of said clauses and, on the other, the end of the uncertainty about the restorative effects that said declaration originates. Thus, after analyzing these effects, the study concludes that said jurisprudence has progressively strengthened consumer protection, contributing to the process of European integration.
\end{abstract}

Keywords: European Union - The Court of Justice of The European Union - Consumer Rights - Unfair terms - Mortgage contracts.

\title{
I. INTRODUCCIÓN
}

El proyecto de integración europea es un proceso de naturaleza política, cultural y económica, que en este último ámbito ha buscado conformar un mercado interior que funcione eficientemente desde el punto de vista económico y eficazmente desde un punto de vista social, esto es, que permita alcanzar el mayor bienestar posible a sus ciudadanos, tal como lo prescribe el artículo 3.3 TUE. En este ámbito, y teniendo como contrapartida a las empresas, tales ciudadanos despliegan sus actividades económicas en dos ámbitos principales: en primer término como trabajadores, aportando a los procesos económicos con la oferta de un importante factor de la producción, y en segundo lugar como consumidores, configurando el elemento clave de la demanda agregada, que es el consumo privado. En ambos roles, el Derecho de la Unión Europea (en adelante UE) ha debido desplegar normas de orden público, económico, de dirección y protección ante la asimetría material que las personas y las empresas exhiben en sus diversas relaciones contractuales. 
En este trabajo se busca sistematizar de qué manera, en el ámbito de la demanda de bienes y servicios, el Derecho europeo ha aportado a la credibilidad, confianza y estabilidad de los procesos económicos, cuestión particularmente importante en tiempos en que el euroescepticismo y los efectos de las últimas crisis económicas han dado argumentos a las críticas hacia las instituciones de la UE. Es así como en la conformación del mercado interior, las normas del Derecho de la Unión y la jurisprudencia del Tribunal de Justicia de la Unión Europea (en adelante TJUE) cumplen un rol central, al desplegar figuras jurídicas destinadas a la mencionada protección, aportando con ello a una mayor confianza en la economía social de mercado. En particular, este trabajo aborda la forma en que se ha aplicado el Derecho de la UE en aquellos casos en que proveedores de servicios financieros han incluido cláusulas abusivas en contratos de préstamos hipotecarios.

Haciendo un símil histórico, puede afirmarse que en el ámbito del Derecho de los Consumidores europeos asistimos a un fenómeno jurídico y social semejante al que se consolidó progresivamente desde hace décadas con las sentencias Walrave, Doná y Bosman, que en el ámbito del Derecho laboral reforzaron la no discriminación por nacionalidad entre trabajadores de los Estados miembros, tanto en el acceso como en el ejercicio del empleo, incluyendo los beneficios sociales, respecto de cualquier regulación laboral; materializando algo tan fundamental para el proyecto europeo, como es la libre circulación de trabajadores y la protección de sus derechos como tales (Del Valle Gálvez,2000: 98). No parece exagerada la comparación, si se tiene en cuenta que en materia de derechos de los consumidores, la Directiva 93/13/ CEE del Consejo tiene como objetivos declarados brindar protección a los consumidores del detrimento de las cláusulas abusivas insertas en los contratos no negociados; proveer a los Estados miembros de un marco normativo que puedan trasponer a sus ordenamientos nacionales, impidiendo que se vincule de manera alguna a los deudores hipotecarios con los efectos de cláusulas abusivas, instando a los Estados para que presionen a los proveedores en orden a que no incluyan este tipo de cláusulas en sus contratos.

Con esta Directiva se avanzó jurídicamente en la conformación de un ambiente seguro para los consumidores, donde la confianza y credibilidad de los mercados es un valor esencial para el desarrollo económico y para el éxito del proceso de integración. Pero dicho marco de protección no se agota en la citada Directiva, ya que de manera progresiva este se ha visto reforzado por la jurisprudencia del tJue. En efecto, en este trabajo se abordará concretamente la manera en que el Derecho de la UE brinda protección a los consumidores afectados por cláusulas abusivas en contratos hipotecarios, y la forma en que dicha protección se ha ampliado progresivamente a través 
de la jurisprudencia del tjue. En este marco, el presente trabajo abordará particularmente dos efectos jurídicos provocados por la mencionada jurisprudencia. En primer término, se analizarán pronunciamientos relevantes para reforzar el principio de efectividad procesal en la nulidad de las cláusulas abusivas en contratos hipotecarios. Y, en segundo término, se abordará la forma en que se han precisado los efectos restitutorios vinculados a la declaración de nulidad de tales cláusulas, impidiendo que tal asunto quede a libre determinación de los tribunales nacionales llamados a conocer en estos asuntos. A partir de estos dos efectos jurídicos aquí analizados se podrá evaluar de qué manera se ha ampliado la protección de los consumidores, a partir de la actuación de la institución europea encargada de velar por la aplicación general y uniforme de las normas sobre derechos de los consumidores en la UE.

\section{LOS EFECTOS JURÍDICOS DE LA JURISPRUDENCIA DEL TJUE Y LA PROGRESIVA AMPLIACIÓN DE LA PROTECCIÓN DE LOS DERECHOS DE LOS CONSUMIDORES EN LOS CONTRATOS HIPOTECARIOS}

En un plano normativo, hasta el año 2007 la protección de los consumidores se consideraba, por parte de la Doctrina, como un ámbito de coordinación y apoyo entre los Estados miembros de la UE y sus instituciones. En el actual diseño de atribución de competencias de la UE, la protección de los consumidores es una competencia compartida por la Unión y los Estados miembros, conforme lo previsto en el artículo 4 del Tratado de Funcionamiento de la Unión Europea (TFUE). En mérito de esta disposición, el ejercicio de competencias para la protección de los consumidores europeos y la aprobación de normas comunitarias en este ámbito cuenta con base jurídica en el Derecho originario de la Unión (Mangas Martín y Liñán
Nogueras, 2012: 74), lo cual refuerza la validez y carácter supranacional de las disposiciones que regulan estas materias. Además, cabe mencionar que el artículo 12 del true dispone que "al definirse y ejecutarse otras políticas y acciones de la Unión, se tendrán en cuenta las exigencias de la protección de los consumidores".En igual sentido, el artículo 38 de la Carta de Derechos Humanos de la UE prescribe que "en las políticas de la Unión se garantizará un nivel elevado de protección de los consumidores".

Teniendo estas normas como punto de partida, la fuerza impulsora de la progresiva ampliación de la protección de los derechos de los consumidores europeos proviene tanto de las directivas comunitarias y normas de 
la UE, ${ }^{1}$ en un plano normativo, como de las sentencias del tJuE, en un plano jurisdiccional. En efecto, en este trabajo se explicará la importancia de algunas sentencias pronunciadas por este Tribunal, que permitieron consolidar la supresión de cláusulas abusivas en las relaciones asimétricas que están detrás de los contratos financieros de adhesión.

En el contexto institucional de la UE, el TJUE se nos presenta como una institución llamada por su propia naturaleza a provocar efectos directos del Derecho de la Unión en el ámbito personal de los ciudadanos europeos, y que a través de sus interpretaciones y pronunciamientos, da lugar a una aplicación general y uniforme de las normas del Derecho de la Unión en este ámbito, en el marco de los procedimientos por cuestiones prejudiciales,

1 Cabe destacar el Reglamento (CE) No 2006/2004 del Parlamento Europeo y del Consejo, de 27 de octubre de 2004, sobre la cooperación entre las autoridades nacionales responsables de la aplicación de las leyes de protección de los consumidores. DO L 364 de 9.12.2004, pp.1-11. en que los jueces nacionales lo llaman a decidir. ${ }^{2}$

En este punto, vale la pena referirse brevemente a la naturaleza jurídica de la norma empleada por la UE para establecer los derechos de los consumidores en el contexto de sistema de fuentes normativas que, como se ha mencionado, es la Directiva 93/13/CEE del Consejo, que brinda protección a los consumidores del detrimento de las cláusulas abusivas insertas en los contratos no negociados. Al tratarse de una Directiva, la norma europea impone a los Estados miembros una obligación de resultado, que consiste en aprobar internamente las normas destinadas a materializar las disposiciones y objetivos previstos en la respectiva Directiva. ${ }^{3}$ De esta manera, a partir de dicho mecanismo, conocido como transposición, surgirán para los particulares los derechos y obligaciones que las Directivas contemplen. Lo

2 Artículo 267 TFUE: "El Tribunal de Justicia de la Unión Europea será competente para pronunciarse, con carácter prejudicial: a) sobre la interpretación de los Tratados; b) sobre la validez e interpretación de los actos adoptados por las instituciones, órganos u organismos de la Unión. Cuando se plantee una cuestión de esta naturaleza ante un órgano jurisdiccional de uno de los Estados miembros, dicho órgano podrá pedir al Tribunal que se pronuncie sobre la misma, si estima necesaria una decisión al respecto para poder emitir su fallo.

3 Artículo 288 TFUE: "La Directiva obligará al Estado miembro destinatario en cuanto al resultado que deba conseguirse, dejando, sin embargo, a las autoridades nacionales la elección de la forma y de los medios”. 
crucial en todo este esquema es que el respectivo Estado asegure el resultado fijado por la Directiva y, como se trata de una obligación imperativa vinculada al principio de "lealtad comunitaria”, deberán cumplirla tanto los órganos legislativos y ejecutivos, así como los tribunales nacionales, que en sus sentencias no podrán apartarse de los objetivos previstos en las directivas.

A mayor abundamiento, en situaciones como las que se analizan en este trabajo, las directivas han sido reconocidas como fuente de Derecho con la suficiente intensidad normativa para ser aplicadas directamente frente a la legislación nacional que resulte contradictoria, tal como se ha determinado en importante jurisprudencia del Tribunal de Justicia de la Unión Europea (Mangas Martín y Liñán Nogueras, 2012: 373).

A partir de la fuerza normativa de las Directivas, en el actual estado de desarrollo del proceso de integración, puede valorarse el efecto de algunas sentencias dictadas en aplicación de la Directiva 93/13/CeE del Consejo, como es el caso de la sentencia del tJue, del 14 de marzo de 2013, Mohamed Aziz, C-415/11, ${ }^{4}$ recaída sobre aplicación de dicha Directiva, en relación a las facultades del Juez Nacional en procedimientos de ejecución hipotecaria frente a la inclusión de cláusulas abusivas en los respectivos contratos de préstamos hipotecarios. Igual valoración

4 TJUE, Sentencia de 14 de marzo de 2013, Aziz, C-415/11, EU:C:2013:164. puede realizarse de la sentencia del TJuE, del 21 de diciembre de 2016, en los asuntos acumulados C-145/15, C-307/15 y C-308/15, recaída en peticiones de decisión prejudicial, para determinar la aplicación del artículo 6, apartado 1 , de la Directiva 93/13/CEe del Consejo, del 5 de abril de 1993.

De esta manera, y en lo que puede calificarse como un efecto social disuasorio, a partir de estas sentencias miles de ciudadanos europeos han visto cómo las entidades bancarias de las que son deudores han retirado de los contratos hipotecarios las denominadas "cláusulas suelo" (Marqués Mosquera, 2014: 251-254). De igual manera, a partir de estas normas y jurisprudencia, cientos de ciudadanos han presentado acciones judiciales con el objeto de paralizar procesos de desahucio. Asimismo, quienes pretendan contratar préstamos hipotecarios, pueden confiar en que tales cláusulas no serán incorporadas en sus contratos y de serlo, podrán anularlas judicialmente, con efectos restitutorios inéditos hasta ahora.

Este resultado jurídico y social se ha materializado a partir de dos efectos provocados por dichas sentencias y que serán objeto de análisis a continuación en este trabajo. Por una parte, se examinará el reforzamiento del principio de efectividad procesal en la nulidad de las cláusulas abusivas en contratos hipotecarios, donde se ha consolidado un sistema de control de validez de los contratos de adhesión hipotecarios. Por otra parte, se analizará la determinación del efecto 
retroactivo de las sentencias que anulan las cláusulas abusivas de los contratos financieros, para efectos de restituciones pecuniarias en favor de los consumidores afectados.

\section{El principio de efectividad procesal en la nulidad de las cláusulas abusivas en contratos hipotecarios}

Entre las definiciones y mecanismos de protección de los consumidores europeos, la citada Directiva 93/13/CEE hace alusión al principio de eficacia jurídica en los mecanismos que los Estados miembros deben contemplar en la protección de los consumidores. Esta norma plantea que los órganos judiciales y autoridades administrativas deben contar con medios apropiados y eficaces para poner fin al uso de cláusulas abusivas en los contratos celebrados con consumidores.

Por la propia naturaleza de las figuras contractuales que se ha querido regular, es habitual que las normas referidas a cláusulas abusivas no entreguen una definición cerrada ni un listado de numerus clausus para describir taxativamente dichas cláusulas. Es así como el Derecho europeo se adhirió a esta tendencia regulatoria y en la Directiva 93/13/CEE del Consejo dispuso en su artículo 3, apartado 1, que las cláusulas contractuales que no se hayan negociado individualmente se considerarán abusivas si, pese a las exigencias de la buenafe, causan en detrimento del consumidor un desequilibrio importante entre los derechos y obligaciones de las partes que se derivan del contrato. Por su parte, el aparatado 2 de dicho artículo complementó lo anterior, disponiendo que se considerará que una cláusula no se ha negociado individualmente cuando haya sido redactada previamente y el consumidor no haya podido influir sobre su contenido, en particular en el caso de los contratos de adhesión. A mayor abundamiento, de manera ejemplar, la norma comunitaria entrega un listado de cláusulas que pueden calificarse como abusivas, admitiendo su ampliación a otras fórmulas en las normas nacionales de trasposición. ${ }^{5}$

Teniendo estas disposiciones en perspectiva, y rechazando las alegaciones de inadmisibilidad de la cuestión prejudicial formuladas por Catalunyacaixa y el Gobierno español, ${ }^{6}$ el TJue dictó la sentencia del 14 de marzo

5 En el Anexo de la Directiva 93/13/CEE se enumeran ejemplos de contenidos contractuales que tengan por objeto o por efecto materializar una cláusula abusiva. Recuperado el 10 de junio de 2019, https://eur-lex. europa.eu/legal-content/ES/TXT/PDF/?uri=CELEX:31993L0013\&from=ES

6 “... La negativa del Tribunal de Justicia a pronunciarse sobre una petición de decisión prejudicial planteada por un órgano jurisdiccional nacional solo está justificada cuando resulta evidente que la interpretación del derecho de la Unión solicitada no tiene relación alguna con la realidad o con el objeto del litigio principal, cuando el problema es de naturaleza hipotética o cuando el Tribunal de Justicia no dispone de los elementos de hecho y Derecho necesarios para responder de manera útil a las cuestiones planteadas... (y) no ocurre así en el presente asunto" (Apartado 35 y 36 de la sentencia) 
de 2013, Mohamed Aziz, C-415/11, en la que examinó la normativa española aplicable a los procedimientos ejecutivos relacionados con contratos hipotecarios, ampliando de manera contundente la protección de los consumidores de estos servicios financieros. En efecto, en el marco de la tramitación del procedimiento prejudicial, ya anticipaban tal efecto las conclusiones de la Abogada General ${ }^{7}$, en las que se dejó constancia de la importancia que esta cuestión tendría para los consumidores europeos, afirmándose que este procedimiento brindaba al tjue la posibilidad de desarrollar su jurisprudencia relativa a la garantía efectiva de la protección al consumidor mediante el derecho procesal nacional.

Lo anterior se debe a que en la especie, siguiendo la jurisprudencia previa

7 Conclusiones de la Abogada General Juliane Kokot, presentadas el 8 de noviembre de 2012, Asunto C-415/11. ECLI:EU:C:2016:552. Apartado 97, N¹1: "Un sistema de ejecución de títulos notariales sobre bienes hipotecados o pignorados, en el que las posibilidades de oposición frente a la ejecución se encuentran restringidas es incompatible con la Directiva 93/13/CEE del Consejo, del 5 de abril de 1993, sobre las cláusulas abusivas en los contratos celebrados con consumidores, cuando el consumidor, ni en el propio procedimiento ejecutivo ni en un procedimiento judicial separado, puede obtener una tutela jurídica efectiva para ejercitar los derechos reconocidos en dicha Directiva, por ejemplo mediante una resolución judicial que suspenda provisionalmente la ejecución forzosa”. Recuperado el 13 de junio de 2019, https:/www.ucm.es/data/cont/docs/9842014-10-20-Conclusiones\%20Abogado\%20 General\%20Caso\%20Aziz.pdf del propio órgano jurisdiccional supranacional, se estableció que el Tribunal Nacional era el encargado de establecer el carácter abusivo de una cláusula, teniendo a su vez especial consideración de las circunstancias particulares que se presenten en cada caso. No obstante ello, el tJue delimitó los elementos básicos que debían presentarse para la calificación de cláusula abusiva, a saber: que la cláusula cause un efecto de desequilibrio importante entre las partes y que dicho desequilibrio sea el resultado de un acto desleal por parte del proveedor. Tal calificación es muy importante, porque de cara al Derecho de la UE de los consumidores, de la manera prevista en la Directiva 93/13/CEE, los proveedores cumplen con las exigencias de buena fe, tratando de manera leal y equitativa con la otra parte, cuyos intereses legítimos deben tener en cuenta (Beltrá Cabello, 2014:60).

Es así como, en lo relativo al fondo del asunto sometido a su conocimiento, el TJue se limitó a establecer una cuestión más bien metodológica, al señalar que el tribunal nacional debe centrar su análisis en la determinación, a la vista de las particulares circunstancias del caso, de si cabría estimar de modo razonable que, tratando de manera leal y equitativa con el consumidor, este aceptaría una cláusula como la controvertida en el marco de una negociación individual, realizando un paralelo entre el resultado de tal negociación y el de la suscripción de un contrato de adhesión. 
Cabe preguntarse, en este punto, si el tjue no calificó como abusiva una cláusula en este asunto, es decir, no entró al fondo de la controversia jurídica, dónde radica la importancia de este fallo. Precisamente, en el acento puesto sobre la eficacia de los mecanismos procesales de protección de los consumidores de servicios hipotecarios. En efecto, la sentencia del TJuE, del 14 de marzo de 2013, Mohamed Aziz, C-415/11, recaída sobre aplicación de la Directiva arriba citada, en relación a las facultades del Juez Nacional en procedimientos de ejecución hipotecaria frente a la inclusión de cláusulas abusivas en los respectivos contratos de préstamos hipotecarios, reafirma el principio de autonomía procesal de los Estados miembros. No obstante ello, propugna de manera contundente el principio de efectividad de las sentencias en relación a la protección de los consumidores. De esta forma, y en lo que aquí se destaca de este fallo, se estableció que la configuración de los procedimientos declarativos para la determinación de la nulidad de una cláusula abusiva en contratos de adhesión y los procedimientos de ejecución hipotecaria, no pueden hacer imposible o excesivamente difícil el ejercicio de los derechos que el ordenamiento comunitario confiere a los consumidores de la UE.

Es así como, de acuerdo a la sentencia Aziz, la normativa española sobre ejecución hipotecaria, al no admitir que en el juicio ejecutivo hipotecario se formulara oposición fundada en el carácter abusivo de una cláusula del contrato hipotecario, que constituye el fundamento del título ejecutivo, ni permitir que el juez civil que - conociendo del proceso declarativo de nulidad - pudiese suspender el procedimiento ejecutivo, contravenía la Directiva 93/13/CEE sobre cláusulas abusivas en contratos celebrados con los consumidores. Ello, por cuanto hace difícil o imposible revertir los efectos del juicio ejecutivo, donde ya podría haberse rematado el inmueble, privando de dicho bien al consumidor, en circunstancias que este habría sido afectado por una cláusula abusiva incluida en el contrato de adhesión financiero por el proveedor, cuya nulidad no se habría declarado oportunamente.

En mérito de ello, y tal como la Doctrina anticipó en su momento (Sánchez González, 2013:338), el legislador español se hizo cargo de lo establecido en la sentencia arriba señalada, aprobándose la Ley 1/13 de 14 de mayo de $2013^{8}$ que realizó una modificación del procedimiento ejecutivo para que el tribunal competente, de oficio o a instancia de parte, pueda apreciar la existencia de cláusulas abusivas en el título ejecutivo y, como consecuencia, decretar la improcedencia de la ejecución o, en su caso, su continuación sin aplicación de aquellas consideradas abusivas. Asimismo, dicho texto legal

8 Ley 1/13 de 14 de mayo de 2013. Recuperado el 20 de junio de 2019, https://www.boe.es/ eli/es/1/2013/05/14/1/con 
asume como parte de lo que denomina "Medidas de mejora del mercado hipotecario", en un contexto de venta extrajudicial, la posibilidad de oponerse a un desahucio de la vivienda alegando haber sido obligado contractualmente con la respectiva entidad financiera o bancaria mediante una cláusula abusiva. Es así como el Artículo 129 letra f) de la Ley Hipotecaria actualmente admite como causa de oposición en el procedimiento de ejecución hipotecaria la existencia de una cláusula abusiva que sea el fundamento de la ejecución, en expresa remisión a la Ley de Enjuiciamiento Civil, disponiendo que cuando el Notario considerase que alguna de las cláusulas del préstamo hipotecario que constituya el fundamento de la venta extrajudicial o que hubiese determinado la cantidad exigible pudiera tener carácter abusivo, lo pondrá en conocimiento de deudor, acreedor y, en su caso, avalista e hipotecante no deudor, a los efectos oportunos.

A mayor abundamiento, a partir de estos efectos se incorporó una nueva causa de oposición a la ejecución, al disponer esta norma que el Notario suspenderá la venta extrajudicial cuando cualquiera de las partes acredite haber planteado ante el Juez que sea competente, conforme a lo establecido en el artículo 684 de la Ley de Enjuiciamiento Civil, el carácter abusivo de dichas cláusulas contractuales. Dicho artículo agrega que la cuestión sobre el carácter abusivo de una cláusula contractual se sustanciará por los trámites y con los efectos previstos para la causa de oposición regulada en el apartado 4 del artículo 695.1 de Ley de Enjuiciamiento Civil.Con ello, una vez sustanciada la cuestión, y siempre que no se trate de una cláusula abusiva que constituya el fundamento de la ejecución, el Notario podrá proseguir la venta extrajudicial a requerimiento del acreedor.

Esta modificación legal ha recibido una amplia valoración social, política y jurídica (Sánchez González, 2013: 327-344; Espín Gutiérrez, 2016), toda vez que las normas procesales y la Ley Hipotecaria antes de la modificación analizada daban el carácter de irreversible a la adjudicación de un bien hipotecado al rematante, aunque la condición abusiva de la cláusula que se impugnase en un procedimiento de lato conocimiento, determinase posteriormente la nulidad del procedimiento de ejecución hipotecaria. Es decir, hasta el pronunciamiento del TJuE los jueces no disponían de atribuciones para suspender una ejecución hipotecaria, no obstante acreditarse que existía un incumplimiento de una cláusula abusiva como causa de pedir en el procedimiento ejecutivo.

El paso de ese escenario a uno en que se amplían las posibilidades del control de validez de las cláusulas abusivas en contratos en que se emplean cláusulas generales, y en particular en los contratos de préstamos hipotecarios, asegurando procesalmente la eficacia de las consecuencias de una declaración de nulidad sobre 
una cláusula abusiva, puede valorarse como una ampliación de la efectiva protección de los consumidores en un ámbito tan sensible como es la adquisición de una vivienda.

\section{Los efectos restitutorios vinculados} a la declaración de nulidad de las cláusulas abusivas en contratos hipotecarios

Como se ha señalado, la Directiva 93/13/CEE abordó en el Derecho de la UE la regulación de las cláusulas abusivas siguiendo la tendencia regulatoria en el Derecho del Consumo, en cuanto a hacerlo de una manera genérica, y entregando en el texto normativo un listado de ejemplos de tales cláusulas que resultarían nulas de pleno derecho. Ahora bien, en lo que dice relación con los efectos de la nulidad de las cláusulas abusivas, la misma Directiva, en su artículo 6, dispone que los Estados miembros establecerán que no vincularán al consumidor, en las condiciones estipuladas por sus derechos nacionales, las cláusulas abusivas que figuren en un contrato celebrado entre este y un profesional, y dispondrán que el contrato siga siendo obligatorio para las partes en los mismos términos, si este puede subsistir sin las cláusulas abusivas. Es así como la Directiva debe trasponerse a los derechos internos con un criterio absoluto en lo relativo a la no afectación del consumidor por los efectos de una cláusula calificada como abusiva, correspondiendo tal calificación a la nulidad absoluta de dicha cláusula en términos civiles.

No obstante ello, las sentencias de tribunales nacionales recaídas en casos de las denominadas "cláusulas suelo" han sido vacilantes al determinar la retroactividad de la nulidad, decantándose en ocasiones por la seguridad jurídica que resguarda la figura de la irretroactividad y, en otras oportunidades, por la aplicación del principio de "no vinculación" de las cláusulas abusivas a los consumidores. Las mencionadas "cláusulas suelo" son un tipo de estipulación contractual incorporada en las condiciones generales de la contratación de préstamos hipotecarios ampliamente utilizada en contratos a interés variable desde el año 2009 en Europa. Básicamente, dadas las bajas tasas aplicadas desde la autoridad monetaria europea luego de la crisis subprime, en dichas cláusulas se indicaba un tope mínimo de la tasa de interés, que solía superar el 3\%, de lo cual deriva su nombre, sin que se fije un máximo (o un techo) a la tasa variable como contrapartida a dicha estipulación. Un aspecto crítico de estas cláusulas es que se encontraban instaladas de manera poco clara en los contratos de adhesión, limitando la posibilidad de que el consumidor realmente comprendiera las implicancias económicas de la aplicación de dicha cláusula.

A este respecto, un caso paradigmático en este derrotero judicial, lo constituyó la Sentencia del Tribunal Supremo español del 9 de mayo de 2013, 
en que se declaró nulas las "cláusulas suelo" por falta de transparencia material, pero en la que se restringieron los efectos retroactivos restitutorios, en base al principio de seguridad jurídica y mantenimiento del orden público económico (Llamas Pombo, 2013). A esta sentencia siguieron otras que confirmaron la limitación temporal de los efectos retroactivos de la declaración de nulidad de estas cláusulas abusivas conocidas como "cláusulas suelo". En los hechos, los consumidores que habían sido víctimas de estas cláusulas no tendrían acceso a recibir la devolución de las sumas que habían pagado en exceso a la banca, la que a su vez había recibido recursos del Banco Central Europeo a tasas de interés inéditas en la última década, lo cual recibió algunos cuestionamientos jurídicos (Valero Fernández-Reyes, 2013:181), reforzando en el plano social la sensación de abuso en los consumidores afectados y en la sociedad en general.

En este escenario, y producto de sendas cuestiones prejudiciales planteadas por tribunales de primera instancia, el TJue tomó conocimiento de ellos en los asuntos acumulados C-145/15, C-307/15 y C-308/15, dictando sentencia en la causa el 21 de diciembre de 2016, recaída en peticiones de decisión prejudicial para determinar la aplicación del artículo 6, apartado 1, de la Directiva 93/13/CeE del Consejo. ${ }^{9}$ En dicha sentencia, el tjue declaró, en definitiva, que "el artículo 6, apartado 1, de la citada Directiva sobre las cláusulas abusivas en los contratos celebrados con consumidores, debe interpretarse en el sentido de que se opone a una jurisprudencia nacional que limita en el tiempo los efectos restitutorios vinculados a la declaración del carácter abusivo, en el sentido del artículo 3, apartado 1, de dicha Directiva, de una cláusula contenida en un contrato celebrado con un consumidor por un profesional, circunscribiendo tales efectos restitutorios exclusivamente a las cantidades pagadas indebidamente en aplicación de tal cláusula con posterioridad al pronunciamiento de la resolución judicial mediante la que se declaró el carácter abusivo de la cláusula en cuestión".

En esta sentencia, el tJue coincidió con el Tribunal Supremo español en el sentido de declarar la nulidad de las "cláusula suelo", entendiendo que estarían viciadas por falta de transparencia material al momento de celebrar el contrato, toda vez que a los consumidores no se les proporcionó de manera clara y transparente la información que les permitiese comprender a cabalidad el contenido de la cláusula y sus posibles efectos jurídicos y económicos. De hecho, en ambas sentencias se dejó establecido que las cláusulas que

9 TJUE, Sentencia de 21 de diciembre de 2016 en los asuntos acumulados C-145/15, C-307/15 y C-308/15. Recuperado el 12 de junio de 2019, http://curia.europa.eu/juris/ document/document_print.jsf?doclan$\mathrm{g}=\mathrm{ES} \& \mathrm{text}=$ \&pageIndex $=0$ \& part $=1 \& \mathrm{mo}-$ $\underline{\mathrm{de}}=$ req\&docid $=186483 \&$ occ $=$ first $\&$ dir $=\&$ cid $=515529$ 
establecían un umbral mínimo por debajo del cual no podrían situarse el tipo de interés variable ("cláusulas suelo") estaban referidas a la definición del objeto principal de los contratos hipotecarios cuestionados, y resultaban gramaticalmente inteligibles para los consumidores, cumpliendo el requisito de redacción clara y comprensible que exige el artículo 4, apartado 2, de la Directiva 93/13/CEE.

No obstante ello, el Tribunal Supremo, acertadamente a juicio del TJUE, consideró que la exigencia de transparencia prevista en la Directiva 93/13/ CEE debe entenderse referida no solo a aspectos formales o de redacción, sino también a aspectos materiales, con el mismo alcance que la exigencia contemplada en el artículo 5 de la citada Directiva ${ }^{10}$ relacionado con el carácter suficiente de la información entregada a los consumidores, en el momento de la celebración del contrato, acerca de las consecuencias jurídicas y económicas derivadas para ellos de la aceptación de las cláusulas relativas al objeto principal del contrato. ${ }^{11}$ En

10 Artículo 5 Directiva 93/13/CEE. “En los casos de contratos en que todas las cláusulas propuestas al consumidor o algunas de ellas consten por escrito, estas cláusulas deberán estar redactadas siempre de forma clara y comprensible. En caso de duda sobre el sentido de una cláusula, prevalecerá la interpretación más favorable para el consumidor. Esta norma de interpretación no será aplicable en el marco de los procedimientos que establece el apartado 2 del artículo 7 de la presente Directiva".

11 Apartados 19, 20 y 21 de la Sentencia del TJUE del 21 de diciembre de 2013. efecto, en su sentencia del 9 de mayo de $2013,{ }^{12}$ el Tribunal Supremo español calificó como objeto principal del contrato de préstamo hipotecario las llamadas "cláusulas suelo" en los intereses variables, sosteniendo que dicha calificación resultaría compatible con la identificación de dichas cláusulas como una condición general de la contratación. Precisamente por ello deberá acreditarse por el proveedor que cumplió con su obligación de informar de manera pormenorizada a sus clientes del significado jurídico y económico que para ellos podía derivarse de la inclusión de la cláusula en el contrato, lo cual no pudo apreciarse en la especie.

De manera coincidente con este razonamiento, el tjue declaró en la sentencia de diciembre de 2016 que "reviste una importancia fundamental para el consumidor disponer, antes de la celebración de un contrato, de información sobre las condiciones contractuales y las consecuencias de dicha celebración. El consumidor decide si desea quedar vinculado por las condiciones redactadas de antemano por el profesional, basándose principalmente en esa información".13

En este orden de ideas, cabe mencionar que la transparencia y acceso a la información de los consumidores y usuarios es un principio general del

12 Sentencia Tribunal Supremo $N^{\circ} 241 / 2013$, del 9 de mayo de 2013. ROJ 1916/2013.

13 TJUE, Sentencia del 21 de diciembre de 2016 en los asuntos acumulados C-145/15, C-307/15 y C-308/15. Apartado 50. 
Derecho del Consumo (De la Maza Gazmuri, 2010:31). En un marco de libertad económica no puede ser de otra manera, ya que los instrumentos de tutela o protección deben ser compatibles con el ejercicio de la libertad de elegir los bienes y servicios que se desean adquirir o utilizar. Por ello, la primera responsabilidad de los consumidores es informarse acerca de las características del bien o servicio y su idoneidad para el fin o necesidad que se desea satisfacer, lo cual en materia de contratos financieros dice relación con conocer y comprender cabalmente las cláusulas y elementos del instrumento jurídico que perfecciona el acto de consumo. En particular, en un préstamo hipotecario estamos ante un contrato de adhesión en que la información es controlada y proporcionada directamente por el proveedor, que además reviste un carácter altamente profesional y especializado, lo cual contrasta con la generalidad de los consumidores que carecen de formación financiera o jurídica de un nivel tal que les permita comprender, comparar y analizar todos los pormenores de un contrato financiero. Es aquí donde el acceso y transparencia de la información se vuelve muy relevante, por lo que la legislación de protección de los consumidores ha debido exigir ciertos estándares que ofrezcan seguridad a los consumidores. ${ }^{14}$

Ahora bien, reconociendo el TJUE que corresponde a los Estados miembros, mediante sus respectivos derechos nacionales, precisar las condiciones con arreglo a las cuales se declare el carácter abusivo de una cláusula y se materialicen los efectos jurídicos de tal declaración, no es menos cierto que la declaración permite que se restablezca la situación de hecho y de Derecho en la que se encontraría el consumidor de no haber existido tal cláusula abusiva, concretamente mediante la constitución de un derecho a la restitución de las ventajas obtenidas indebidamente por el profesional en detrimento del consumidor en virtud de la cláusula abusiva. ${ }^{15}$ Tal conclusión es absolutamente coherente con la argumentación relativa a la nulidad de la cláusula que el propio tJue ofreció en su sentencia y

14 Cabe destacar en este punto el fortalecimiento del principio de transparencia en los contratos financieros, principalmente a través de la Directiva 2014/17/UE, del 4 de febrero de 2014, sobre los contratos de crédito celebrados con los consumidores para bienes inmuebles de uso residencial y por la que se modifican las Directivas 2008/48/ CE y 2013/36/UE y el Reglamento (UE) no 1093/2010. Con este texto normativo la Unión Europea armoniza la normativa en materia hipotecaria y financiación a particulares en los Estados Miembros, creando un marco común que refuerza la posición de los ciudadanos europeos frente a las entidades bancarias y de financiación hipotecaria. Recuperado el 25 de junio de 2019, https://eur-lex.europa.eu/legal-content/ES/ $\mathrm{TXT} / \mathrm{PDF} /$ ? u ri = C E L E X : 32014 L0017\&from $=$ EN

15 Apartado 66 de la Sentencia del TJUE, del 21 de diciembre de 2013. 
en reiterada jurisprudencia, ${ }^{16}$ toda vez que afirma la improcedencia de que el juez nacional modifique o corrija cláusulas abusivas en las causas que deba conocer, ya que el artículo 4 de la Directiva 93/13/CEE no deja lugar a dudas en cuanto a que la calificación de abusiva de una cláusula provocará que, pura y simplemente, tales cláusulas no se apliquen frente a los consumidores (Platero Alcón, González González, 2017:203).

De esta manera, el tJue estableció dos cuestiones de máxima importancia. En primer término reiteró su criterio en cuanto a que el juez nacional debe apreciar de oficio el carácter abusivo de una cláusula contractual incluida en el ámbito de ampliación de la Directiva 93/13/CEe y, de este modo, subsanar el desequilibrio que existe entre el consumidor y el profesional, desde el momento en que se disponga de los elementos de hecho y de Derecho necesarios al efecto, sin esperar a que el consumidor presente una declaración por la que solicite anular una cláusula. ${ }^{17}$

En segundo lugar, el TJue estableció que debe considerarse que una cláusula contractual declarada judicialmente

16 TJUE, Sentencia del 21 de enero de 2015, Unicaja Banco y Caixabank, C-482/13, C-484/13, C-485/13, C-487/13, EU:C:2015:21, apartado 31. Sentencia Banco Español de Crédito, EU:C:2012:349, apartado 69. Sentencia Kásler y Káslerné Rábai, EU:C:2014:282, apartado 79.

17 Aplicación de Sentencia del 30 de mayo de 2013, Joros, C-397/11, EU:C:2013:340, Apartado 42. abusiva nunca ha existido, de manera que no podrá tener efectos frente al consumidor. Por consiguiente, la declaración judicial del carácter abusivo de tal cláusula debe restablecer la situación de hecho y de Derecho en la que se encontraba el consumidor de no haber existido dicha cláusula. Por ello, la obligación del juez nacional de dejar una cláusula abusiva sin efecto que imponga el pago de importes que resulten ser cantidades indebidamente pagadas, genera el correspondiente efecto restitutorio de tales importes.

De esta forma, en relación a lo dispuesto en la Directiva 93/13/CEE, el TJuE asumió el rol de único tribunal que puede interpretar una norma del Derecho de la Unión, habida cuenta de la exigencia fundamental de contar con una aplicación uniforme de dicho ordenamiento jurídico. Por ello, es el único tribunal que puede decidir acerca de las limitaciones en el tiempo que hayan de aplicarse a la interpretación que el mismo tribunal realice sobre una norma del Derecho de la Unión. Con la autoridad que dicha atribución le confiere, el tjue se apartó de lo resuelto por los tribunales nacionales y por el Tribunal Supremo español en particular, estableciendo que la restitución de importes indebidamente percibidos por el proveedor no se limita a la fecha de la declaración judicial de nulidad de una cláusula abusiva, sino que debe abarcar íntegramente toda suma cobrada de manera ilícita a los consumidores. Con ello, la jurisprudencia del máximo tribunal europeo 
sustenta el predominio de las nociones de orden público económico de protección por sobre el principio de seguridad jurídica, que tradicionalmente es planteado como contrapartida en este tipo de situaciones.

\section{ConCLuSIÓN}

En este trabajo se han analizado los principales hitos jurisprudenciales que han dado lugar a una progresiva ampliación de la protección de los consumidores afectados por cláusulas abusivas incorporadas en contratos hipotecarios, abordando la importancia del principio de efectividad procesal en la aplicación de la nulidad de cláusulas abusivas en contratos hipotecarios y el fin de la incertidumbre respecto de los efectos restitutorios vinculados a la declaración de nulidad de una cláusula abusiva en contratos hipotecarios.

En primer término, respecto de la efectividad procesal para la debida cautela de derechos, las sentencias analizadas en este trabajo muestran cómo el tJue ha reforzado la protección jurídica de los consumidores de créditos hipotecarios, manteniendo el principio de competencia del tribunal nacional para calificar las cláusulas abusivas en los contratos que sean motivo de litigio. En efecto, sin alterar el citado principio, la acción institucional del tJue ha ofrecido mejores perspectivas de protección jurídica a los consumidores, sin afectar tampoco el principio contenido en el artículo 3 de la Directiva 93/13/CEE, que al definir las cláusulas abusivas se remite a los conceptos de buena fe y de desequilibrio importante entre los derechos y obligaciones de las partes contratantes, delimita de manera abstracta los elementos que confieren carácter abusivo a una cláusula, y deja al juez nacional la calificación para el caso concreto. Es decir, a partir de lo resuelto en estas sentencias y adoptando la superioridad jurisdiccional prevista en los Tratados para el desempeño de su rol de velar por la interpretación y aplicación uniforme de las normas de la Unión, el tjue ha contribuido a ampliar las posibilidades de intervención eficaz del Juez Nacional, para evitar la afectación de los consumidores por cláusulas abusivas incorporadas a los contratos de préstamos hipotecarios.

Como se ha señalado, por su propia naturaleza y de acuerdo a la arquitectura del sistema jurisdiccional de la UE, esta sentencia vinculó a todos los tribunales nacionales de la Unión que conozcan de un asunto similar al caso Aziz, esto es, procedimientos ejecutivos en el marco de contratos hipotecarios, que pudiesen tener vinculado al título ejecutivo el incumplimiento de una cláusula abusiva contenida en un contrato de adhesión. No cabe duda, que esto provocó alivio a las personas que lamentablemente se 
vieron inmersas en procedimientos de desahucio, contando a partir de este fallo con herramientas procesales efectivas para litigar contra empresas que actuando de mala fe, pretendan abusar del evidente desequilibrio material con que se enfrentan a los consumidores.

En segundo término, en relación al fin de la incertidumbre respecto de los efectos restitutorios vinculados a la declaración de nulidad de una cláusula abusiva en contratos hipotecarios, la sentencia pronunciada en los asuntos acumulados C-145/15, C-307/15 y C-308/15, del 21 de diciembre de 2016, recaída en peticiones de decisión prejudicial, propugna un principio clave en materia del Derecho de los consumidores, cual es el de superar las nociones clásicas del Derecho Civil centradas en el equilibrio formal de las partes, la igualdad ante la ley y la autonomía de la voluntad, avanzando en el reconocimiento explícito de la existencia de un desequilibrio material entre las partes de estos contra$\operatorname{tos}^{18}$, situación que conforma un hecho económico que el legislador y el juez deben tener en cuenta a la hora de proteger al contratante débil de esta relación, aplicando criterios de orden público económico. ${ }^{19}$

18 TJUE. Sentencia del 14 de junio de 2012, Banco Español de Crédito, C-618/10, EU:C:2012:349. Apartado 63.

19 TJUE. Sentencia del 30 de mayo de 2013, Asbeek Brusse y de Man Garabito, C-488/11, EU:C:2013:341. Apartado 44.
Es así como, en relación a los efectos de la declaración de una cláusula abusiva en un contrato hipotecario, el tjue estableció de manera general y evitando futuras sentencias contradictorias, que la restitución de importes indebidamente percibidos por el proveedor no se debe limitar a la fecha de la declaración judicial de nulidad de una cláusula abusiva, sino que debe abarcar íntegramente toda suma cobrada de manera ilícita a los consumidores. ${ }^{20}$

De esta manera, $y$ al igual que en el caso anterior, el tjue asumió su rol de velar por la aplicación general y uniforme de las normas sobre derechos de los consumidores de la UE, reforzando efectivamente el sistema de control judicial de las cláusulas abusivas, al disponer que incumbe al Juez Nacional, pura y simplemente dejar sin aplicación una cláusula contractual abusiva, a fin de que esta no produzca efectos vinculantes para el consumidor.

Junto a ello, el tribunal reafirmó que la Directiva 93/13/CEE contiene normas equivalentes a las que en el derecho nacional de los Estados miembros se conocen como normas de orden público, imponiendo claramente la noción de que el juez nacional debe apreciar de oficio el carácter abusivo de una cláusula contractual incluida en el ámbito de aplicación de la citada Directiva, subsanando el desequilibrio

20 TJUE. Sentencia del 21 de diciembre de 2016 en los asuntos acumulados C-145/15, C-307/15 y C-308/15. Apartado 72. 
que pueda presentarse entre el consumidor y el profesional o proveedor, desde el momento en que disponga de los elementos de hecho y de Derecho necesarios al efecto.

En términos generales, a partir de lo analizado en este trabajo, y teniendo en cuenta que las sentencias prejudiciales de interpretación del tJuE tienen efecto que vincula a todos los órganos jurisdiccionales de los Estados miembros (Mangas Martín y Liñán Nogueras, 2012: 462), puede concluirse que en estos casos los procedimientos de decisión prejudicial se posicionan como un mecanismo idóneo para la protección efectiva de los consumidores y usuarios europeos, que en caso de no encontrar el debido amparo en las legislaciones y tribunales nacionales pueden acudir a los procedimientos jurisdiccionales europeos, solicitando la correcta aplicación de las normas del Derecho de la Unión, que a su vez forman parte del orden público económico europeo.

De esta manera, al igual como un día lo hiciera para asegurar la libre movilidad de los trabajadores europeos y la debida protección de sus derechos laborales, progresivamente el tJue ha contribuido a ampliar el marco de protección de los derechos de los consumidores europeos en un aspecto tan relevante como son los préstamos hipotecarios y el acceso a la vivienda. Este concreto aporte a la configuración de un escenario con más seguridad jurídica, credibilidad y confianza para los ciudadanos en sus diversos roles económicos, hace difícil sostener que de parte del tJue exista indiferencia o desafección al momento de ejercer sus atribuciones en relación a las circunstancias que determinan la calidad de vida y el bienestar de dichos ciudadanos. Por el contrario, bien puede calificarse a estos hitos jurisprudenciales como un nuevo paso en el fortalecimiento de la integración política y económica europea, ya que desde su rol el TJue está contribuyendo a legitimar a las instituciones europeas como garantes de un proceso de integración política y económica que no puede sostenerse sin respetar cabalmente los derechos de sus ciudadanos.

\section{Bibliografía}

Beltrá,C. (2014)."Disconformidad del derecho español con la directiva 93/13/CEE al imposibilitarse la alegación del carácter abusivo de cláusulas del contrato en el marco del procedimiento". Revista práctica de Derecho. Comentarios y casos prácticos. $\mathrm{N}^{\circ} 161$.
Espín, C. (2016). "La nulidad de las cláusulas suelo en los contratos a interés variable. En María de la Sierra Flores (Dir.). El préstamo hipotecario y el mercado del crédito en la Unión Europea. Madrid: Dykinson. 
De la Maza, Í. (2010). "El suministro de información como técnica de protección de los consumidores: los deberes precontractuales de información". Revista de Derecho UCN, 17. 2.

Del Valle, A. (2000) "La libre circulación de trabajadores”, en López Escudero Manuel - Martín y Pérez de Nanclares, José (Coord.) Derecho Comunitario Material. Madrid: Mc Graw Hill. 95-105.

Llamas, E. (2013). "La nulidad de las cláusulas suelo”. Ars Iuris Salmanticencis, $\mathrm{N}^{\circ} 1$. Mangas, A. y Liñán, D. (2012). Instituciones y Derecho de la Unión Europea. Madrid: Tecnos.

Marqués, C. (2014). "Las cláusulas suelo". Cuadernos de Derecho y Comercio, $\mathrm{N}^{\circ} 1$.

Platero, A. y González, M.A. (2017). "Las cláusulas abusivas en los contratos hipotecarios en España: especial referencia a las denominadas cláusulas suelo". Lex, Nº 20, Año XV, 2017-II. Recuperado de http://dx.doi.org/10.21503/lex.v15i20.1439

Sánchez, M.P. (2013). “Incidencia del carácter abusivo de una cláusula contractual sobre el procedimiento de ejecución hipotecaria". Revista de Derecho Comunitario Europeo, $\mathrm{N}^{\circ}$ 44, enero/abril. Madrid. STS N²41/2013, del 9 de mayo de 2013. ROJ 1916/2013.
TJUE. Sentencia del 21 de diciembre de 2016 en los asuntos acumulados C-145/15, C-307/15 y C-308/15. ECLI:EU:C:2016:980. TJUE. Sentencia del 21 de enero de 2015. Unicaja Banco y Caixabank, C-482/13, C-484/13, C-485/13, C-487/13, EU:C:2015:21. TJUE. Sentencia del 30 de abril de 2014. Kásler y Káslerné Rábai, C-26/13.

TJUE. Sentencia del 30 de mayo de 2013. Asbeek Brusse y de Man Garabito, C-488/11, EU:C:2013:341.

TJUE. Sentencia del 14 de marzo de 2013. Aziz, C-415/11, EU:C:2013:164.

TJUE. Sentencia del 14 de junio de 2012. Banco Español de Crédito, C-618/10, EU:C:2012:349.

Valero, Á. (2013). "Comentario de la sentencia del Tribunal Supremo del 9 de mayo de 2013 (1916/2013)”, p. 181. Recuperado de https://www.boe.es/publicaciones/comentarios_sentencias_unificacion doctrina civil y mercantil/ abrir_pdf.php?id=COM-D-2013-9 Comentarios_a las_Sentencias_de_Unificacion_de_Doctrina_Civil_y_Mercantil Consumidores: Condiciones Generales_Abusivas._Cl\%C3\%A1usula_Suelo_en_los_Pr\%C3\%A9stamos Hipotecarios. Efectos de su Nulidad 
